\title{
THE VALUE OF EARLY MOBILISATION IN THE TREATMENT OF COLLES' FRACTURES
}

\author{
J. J. DIAS, C. C. WRAY, J. M. JONES, P. J. GREGG \\ From the Leicester Royal Infirmary
}

\begin{abstract}
Unilateral Colles' fractures in 187 patients over the age of 55 years were studied in a randomised prospective trial: 97 fractures were minimally displaced and were treated either conventionally or in a crêpe bandage; 90 displaced Colles' fractures were reduced and of these 47 were treated conventionally while 43 were encouraged to mobilise the wrist in a cast which restricted extension.

Early wrist movement hastened functional recovery and led to earlier resolution of wrist swelling. Discomfort was no greater than in patients who were treated conventionally. The bony deformity, which recurred irrespective of the method of treatment, was not adversely affected by early mobilisation.
\end{abstract}

Colles' fracture can lead to prolonged functional impairment, especially in older patients (Bacorn and Kurtkze 1953). Some authors have noted that over $17 \%$ of patients had poor function one year after injury (Gartland and Werley 1951; Bacorn and Kurtkze 1953; Golden 1963), but others have reported more encouraging recovery as early as six months after the fracture (Pool 1973; Sarmiento et al. 1975; Stewart, Innes and Burke 1984). The disability after Colles' fracture has been attributed to bony deformity, and the importance of obtaining an anatomical reduction has been repeatedly emphasised (Gartland and Werley 1951 ; van der Linden and Ericson 1981; Stewart et al. 1984). Cooney, Dobyns and Lindscheid (1980), however, pointed out that the softtissue injury was partly responsible for the resulting stiffness. After early mobilisation of an injury, the blood supply to bone and soft tissues returns rapidly to normal and joint stiffness is decreased (Müller et al. 1979; Salter et al. 1980). Sarmiento et al. (1975) encouraged wrist movement in a cast brace applied one week after intraarticular Colles' fractures and claimed $82 \%$ satisfactory results without significant deformity. On the other hand Stewart et al. (1984), using an orthoplast brace 10 days after injury, were unable to demonstrate any advantage in early mobilisation over conventional treatment six months after the fracture.

In view of these conflicting reports we studied 187 patients with Colles' fractures to determine whether mobilisation of the wrist from the outset resulted in

J. J. Dias, FRCS Ed, Lecturer

C. C. Wray, FRCS, Registrar

J. M. Jones, FRCS, Consultant

P. J. Gregg, MD, FRCS, Professor

Department of Orthopaedic Surgery, Leicester Royal Infirmary, Infirmary Square, Leicester LE1 SWW, England.

Requests for reprints should be sent to Mr J. J. Dias.

(C) 1987 British Editorial Society of Bone and Joint Surgery 0301-620X/87/3084\$2.00
Table I. Treatment protocol for 187 patients with Colles' fracture*

\begin{tabular}{|c|c|c|c|}
\hline Category & Group & Number & Treatment \\
\hline \multirow[t]{2}{*}{ Undisplaced (97) } & 1 & 47 & Conventional cast 5 weeks \\
\hline & 2 & 50 & $\begin{array}{l}\text { Crépe bandage and early } \\
\text { mobilisation }\end{array}$ \\
\hline \multirow[t]{2}{*}{ Displaced (90) } & 3 & 47 & Conventional cast 5 weeks \\
\hline & 4 & 43 & Modified cast 5 weeks \\
\hline
\end{tabular}

* All patients were initially treated in high slings, and finger and shoulder movements were encouraged

quicker functional recovery and to determine whether pain, swelling and the bony deformity were influenced by this method of treatment.

\section{PATIENTS AND METHODS}

Between October 1984 and May 1985, 187 patients with unilateral Colles' fractures presenting within 24 hours of injury at the Leicester Royal Infirmary were studied prospectively. The criteria for inclusion in the trial were that the patient was over 55 years old, had not previously injured the same hand or wrist, had no injury to the other hand or wrist, had no generalised joint disease and, before the injury, was able to perform daily activities. This particular age group was chosen for study because these patients have previously been shown to have poorer results (Bacorn and Kurtkze 1953). The other wrist had to be essentially normal as it was used for purposes of comparison. There were 26 men and 161 women whose ages ranged from 55 to 98 years (mean 67.2 years).

The fractures were divided into two categories, undisplaced or displaced, depending on whether reduction was needed (some undisplaced fractures did have minimal radiological deformity). The treatment protocol followed is outlined in Table I. For nearly half the 


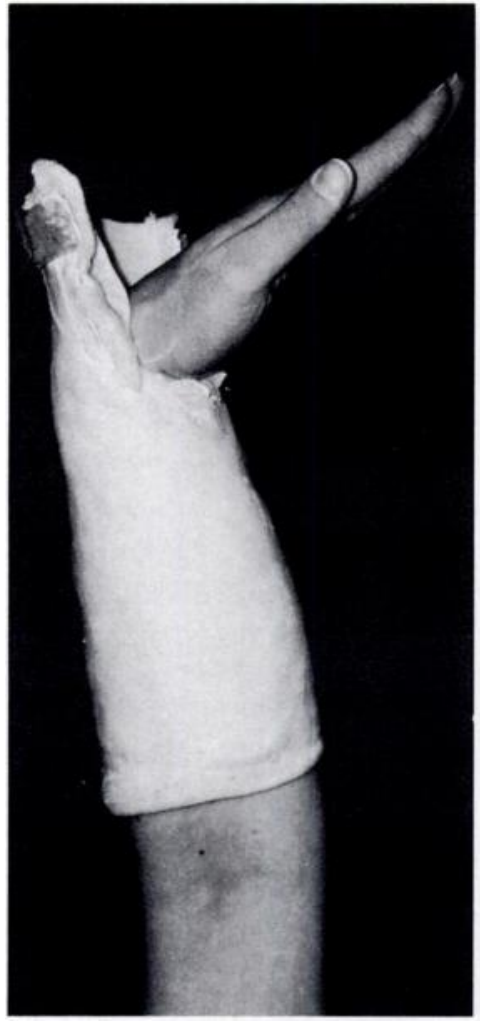

Fig. 1
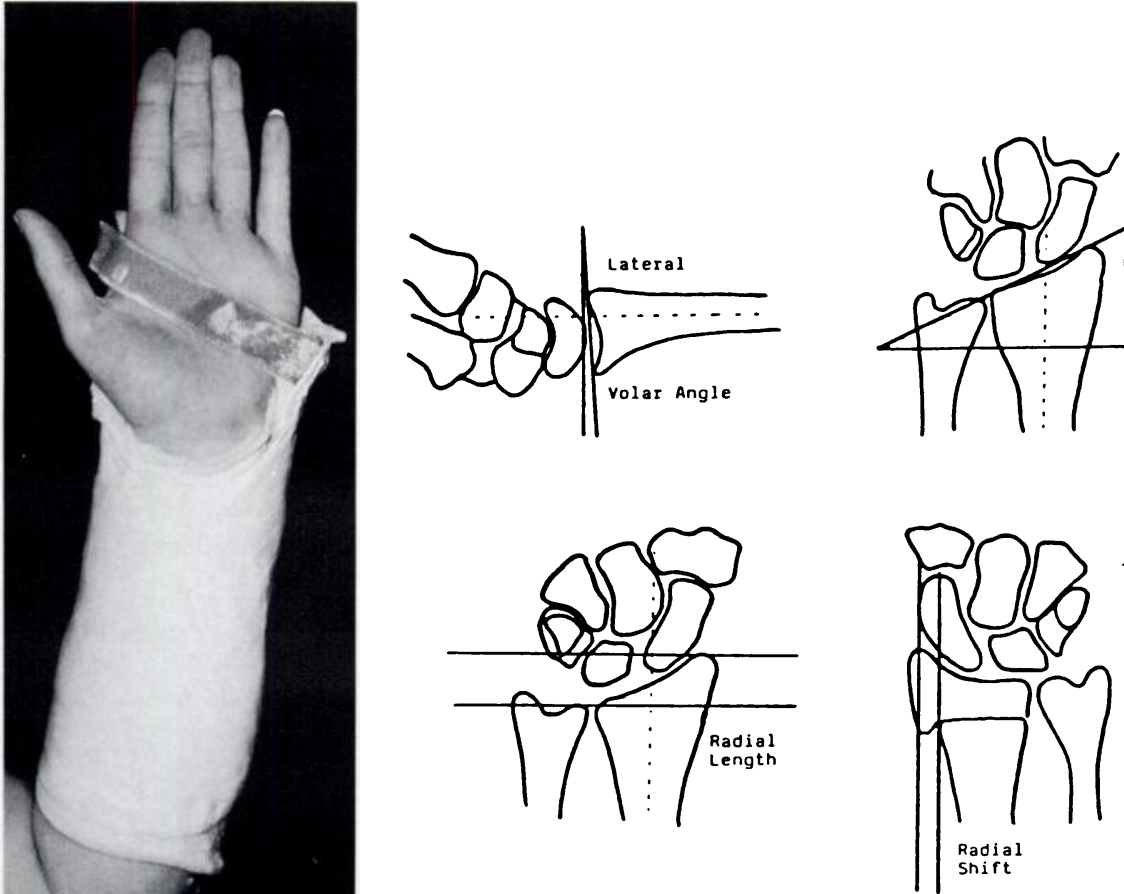

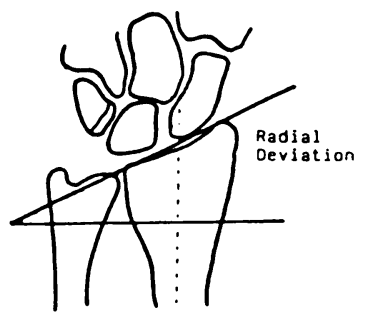

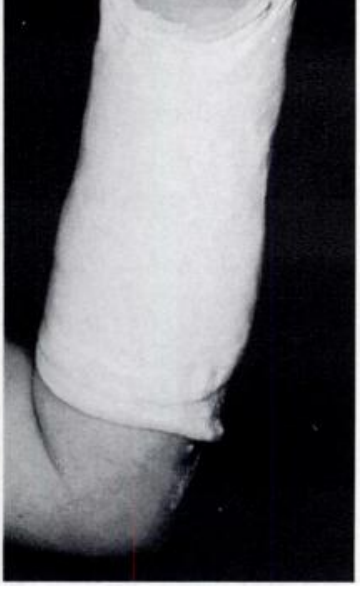

Fig. 2

Fig. 3

Figures 1 and 2 - Patients in Group 4 (displaced fractures) were treated in a below-elbow plaster cast with the wrist in neutral position and the volar aspect of the cast cut back to the proximal wrist crease. A velcro strap was fixed across the palm and the patient was instructed to unfasten the strap each morning and to use the hand as much as comfortably possible throughout the day, re-fastening the strap at night. Figure 3 - The method of radiographic measurement. The sum of these four measurements expressed as the difference from similar measurements made on the normal contralateral wrist was used as an index of the bony deformity.

Undisplaced Fractures

Conventional cast

Crepe bandage
$[100$

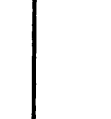

Displaced Fractures

Conventional cast

Modified cast

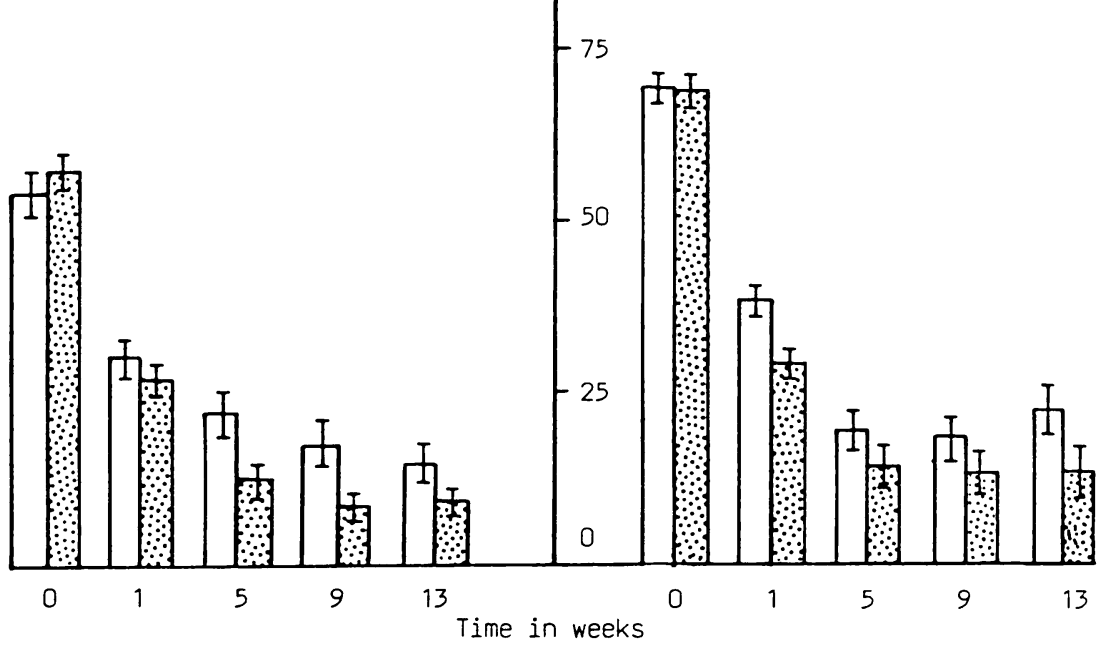

t-test: 2 tail probability $>0.1$

Fig. 4

Pain intensity measured on a pain analogue scale. There is no difference between the two types of fracture. 


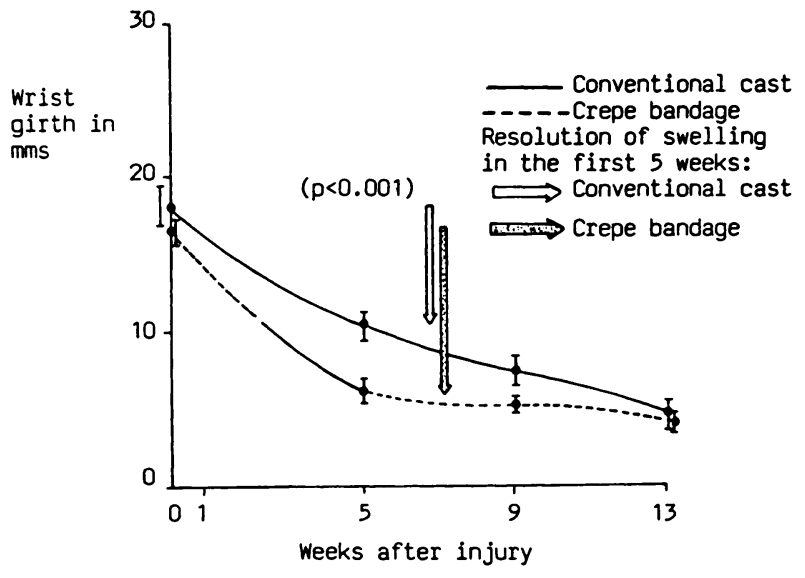

Fig. 5

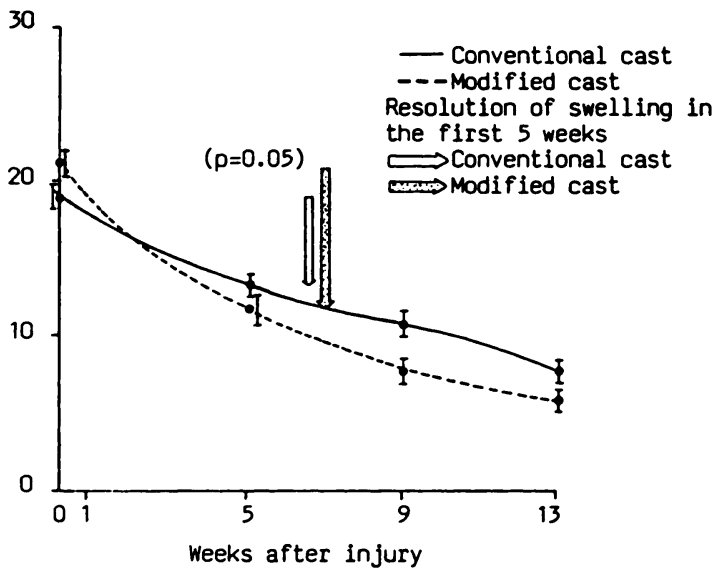

Fig. 6

Figures 5 and 6 - Resolution of wrist swelling. The arrows show the magnitude of resolution of swelling in the first five weeks.

patients with undisplaced fractures (Group 2) no plaster was used and early mobilisation was encouraged while for nearly half of those with displaced fractures (Group 4) a modified cast (Figs 1 and 2) was used. The remaining patients (Groups 1 and 3 ) were treated in a conventional cast.

Each patient was reviewed at one, five, nine and 13 weeks after injury. At each visit the site and severity of pain (using an anologue scale), the amount and type of analgesic needed and the presence of night pain were all noted, and the circumference of the wrist at the ulnar styloid was compared to that of the opposite side.

Flexion, extension, radial and ulnar deviation of the wrist, forearm rotation and metacarpophalangeal and interphalangeal joint movements were recorded using a goniometer. The grip strength in both hands was assessed using a dynamometer. Standard anteroposterior and true lateral radiographs of the wrist and hand also were obtained at each visit; similar radiographs of the other wrist were obtained for comparison. The deformity was measured radiographically, using the method described by Stewart et al. (1984) (Fig. 3).

The final review was undertaken by an independent observer (JMJ). The functional score (Stewart et al. 1984) and the anatomical score (Lidström 1959) were calculated.

\section{RESULTS}

The two groups in each category (undisplaced and displaced fractures) were similar in age, sex distribution, initial deformity and fracture type, initial site and severity of pain and initial wrist swelling $(p>0.1$ for each variable using Student's $t$-test).

Early mobilisation of the wrist did not increase discomfort in Group 2 (those with undisplaced fractures treated without plaster) or in Group 4 (those with displaced fractures in a modified cast) (Fig. 4); nor was the amount of analgesia or the incidence of night pain increased at any time in the study period $(p>0.1)$. At 13 weeks after injury most patients with discomfort felt it to be in region of the radio-ulnar joint; in the group with displaced fractures, 31 of 67 patients with initial pain at this site still had discomfort.

In both categories early mobilisation led to more rapid resolution of wrist swelling in the first five weeks $(p<0.005)$. At nine weeks and at 13 weeks the wrist girths were similar (Figs 5 and 6).

Functional recovery. Patients encouraged to mobilise the injured wrist from the outset recovered wrist movement more quickly than those immobilised in a conventional plaster cast. By the fifth week patients with undisplaced fractures treated in a crêpe bandage had regained $76 \%$ of the movement in the other (normal) wrist, while those treated in plaster took 13 weeks to regain a comparable range of movement (Fig. 7).

Patients with displaced fractures treated in a modified cast regained $54 \%$ of the wrist movements by five weeks, while those treated conventionally had only $28 \%$ of the range in the other wrist; these figures increased over the subsequent eight weeks to $83 \%$ and $74 \%$ respectively (Fig. 8 ).

In all groups the recovery of forearm rotation and finger movement paralleled the recovery of wrist function; for both types of fracture, early mobilisation led to an earlier return of strength (Table II), although

Table II. Grip strength recovery expressed as a percentage of the strength of the contralateral hand ( $p$ values shown in brackets)

\begin{tabular}{clll}
\hline & \multicolumn{3}{l}{ Weeks after fracture } \\
\cline { 2 - 4 } & Sth & 9th & 13th \\
\hline $\begin{array}{llll}\text { Undisplaced fractures } \\
\quad \text { Group 1 }\end{array}$ & 36.1 & 51.7 & 58.3 \\
Group 2 & 45.7 & 63.5 & 76.2 \\
& $(0.000)$ & $(0.005)$ & $(0.000)$ \\
& & & \\
$\begin{array}{c}\text { Displaced fractures } \\
\text { Group 3 } \\
\text { Group 4 }\end{array}$ & 25.0 & 44.0 & 60.1 \\
& 33.4 & 48.8 & 62.7 \\
& $(0.016)$ & $(0.215)$ & $(0.540)$ \\
\hline
\end{tabular}




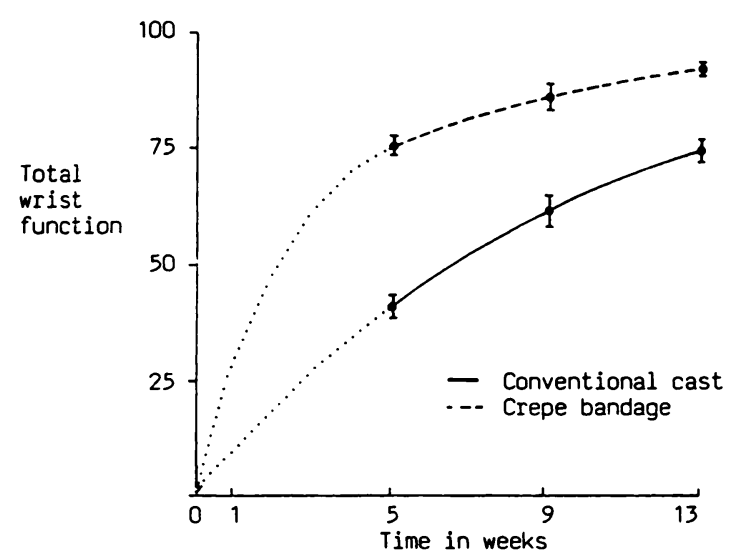

Fig. 7

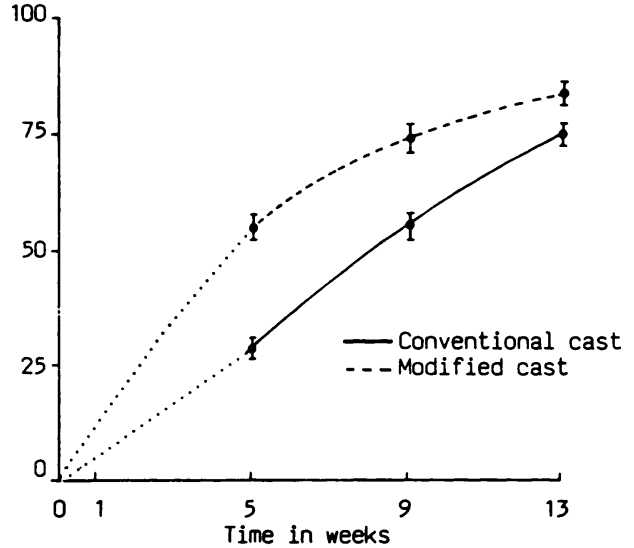

Fig. 8

Figures 7 and 8 - Recovery of wrist movement. The total wrist function was calculated as the sum of flexion, extension, radial deviation and ulnar deviation expressed as a percentage of the corresponding movement of the contralateral (normal) wrist.

this recovery did not parallel the improvement in wrist movement.

Bony deformity. The radiological deformity deteriorated regardless of the method of treatment (Figs 9 and 10). Moreover, in patients who were mobilised early, the rate of deterioration was similar to that in patients who were treated conventionally. In patients with undisplaced fractures, the volar tilt worsened by $5^{\circ}$, the radial deviation by $2^{\circ}$, the radial length by $2 \mathrm{~mm}$ and the radial shift by $0.5 \mathrm{~mm}$. In those with displaced fractures (Fig. 10) there was an early phase of rapid deterioration in spite of the plaster cast; this was followed by slow progression of the deformity over the subsequent eight weeks, long after plaster immobilisation had been discontinued.

\section{DISCUSSION}

This study supports Smaill's (1965) observation that good function may be present in spite of marked residual bony deformity (Table III). The correlation between the

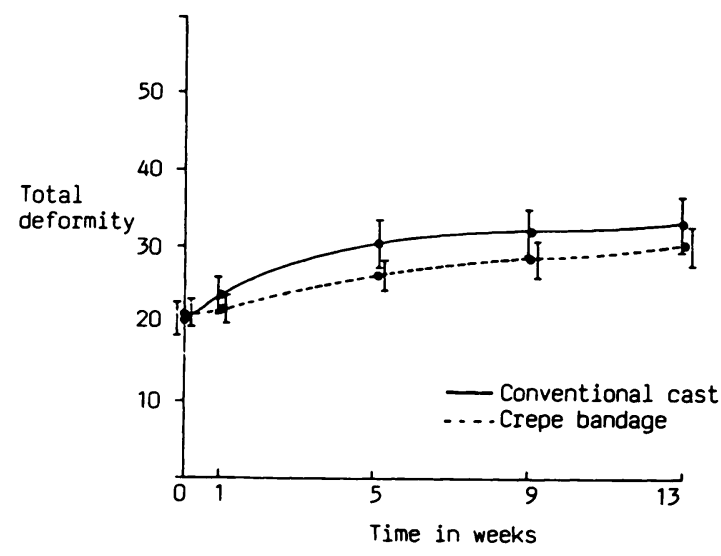

Fig. 9 functional outcome and the bony deformity at the initial visit (Golden 1963), after reduction (Gartland and Werley 1951; van der Linden and Ericson 1981; Stewart et al. 1984), or after bony union (Gartland and Werley 1951; Bacorn and Kurtkze 1953) is probably due to the severity of the soft-tissue injury; this, in our opinion, is the major determinant of the functional outcome. Early mobilisation has been shown to hasten resolution of swelling and to prevent stiffness (Müller et al. 1979; Salter et al. 1980), and this appears to be true of Colles' fractures in patients over 55 years old.

Patients who had the injured wrist mobilised from the outset, either in a crêpe bandage for undisplaced fractures or in a modified cast for displaced fractures, recovered movement and strength more quickly than those treated in a plaster cast. In addition, early wrist mobilisation led to rapid resolution of wrist and hand swelling.

Although in this study we encouraged early wrist movement, our two major concerns were that this might cause more pain and that the bony deformity might be

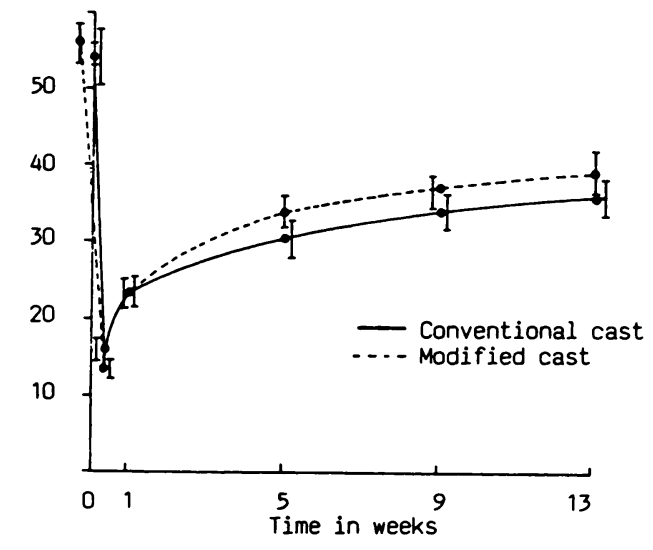

Fig. 10

Figures 9 and 10 - The radiological deformity, which deteriorated regardless of the method of treatment and was similar for all groups. 
Table III. Functional and anatomical outcome expressed as percentages

\begin{tabular}{|c|c|c|c|c|}
\hline \multirow[b]{2}{*}{ Results } & \multicolumn{2}{|c|}{ Undisplaced fractures } & \multicolumn{2}{|c|}{ Dlaplaced fractures } \\
\hline & Group 1 & Group 2 & Group 3 & Group 4 \\
\hline $\begin{array}{c}\text { Functional score } \\
\text { Excellent } \\
\text { Good } \\
\text { Fair } \\
\text { Poor }\end{array}$ & $\begin{array}{c}\text { (after Gart } \\
6.4 \\
38.3 \\
44.7 \\
10.6\end{array}$ & $\begin{array}{l}\text { and Werl } \\
24.0 \\
50.0 \\
26.0 \\
0.0\end{array}$ & $\begin{array}{r}951) \\
6.4 \\
23.4 \\
59.6 \\
10.6\end{array}$ & $\begin{array}{r}16.3 \\
51.2 \\
27.9 \\
4.7\end{array}$ \\
\hline $\begin{array}{c}\text { Anatomical scor } \\
\text { Excellent } \\
\text { Good } \\
\text { Fair } \\
\text { Poor }\end{array}$ & $\begin{array}{l}\text { (after Lids } \\
4.3 \\
55.3 \\
19.1 \\
21.3\end{array}$ & $\begin{array}{l}\text { 1959) } \\
22.0 \\
34.0 \\
28.0 \\
16.0\end{array}$ & $\begin{array}{r}8.5 \\
34.0 \\
38.3 \\
19.1\end{array}$ & $\begin{array}{r}7.0 \\
34.9 \\
41.9 \\
16.3\end{array}$ \\
\hline Total & 47 & 50 & 47 & 43 \\
\hline
\end{tabular}

adversely affected. Our patients were advised to use the wrist and hand only within the limits of comfort, and no patient abandoned early mobilisation for a plaster cast because of pain. Regardless of the method of treatment, the deformity recurred, as documented in almost all previous studies (Gartland and Werley 1951; Pool 1973; Sarmiento et al. 1975; Cooney et al. 1980; Stewart et al. 1984). Early mobilisation did not influence the magnitude or the rate of deterioration of the bony deformity.

Early mobilisation thus resulted in rapid recovery of both movement and strength without causing increased discomfort or adversely influencing the progression of the deformity. In patients over 55, minimally displaced fractures can safely be treated in a crêpe bandage, and displaced fractures which have been reduced can be treated in a modified cast. Early mobilisation would ensure rapid recovery of wrist and hand function while avoiding the complications of a conventional plaster cast.

\section{ACKNOWLEDGEMENT}

We are indebted to the consultants in orthopaedic surgery for giving us access to their patients, to the fracture clinic staff for their cooperation, to Miss S. Hollyoake for secretarial assistance and to the medical illustration department for the illustrations.

\section{REFERENCES}

Bacom RW, Kurtkze JF. Colles' fracture : a study of two thousand cases from the New York State Workman's Compensation Board. $J$ Bone Joint Surg [Am] 1953;35-A :643-58.

Coomey WP III, Dobyms JH, Linacheid RL. Complications of Colles' fractures. J Bone Joint Surg [Am] 1980;62-A :613-9.

Gartland JJ Jr, Werley CW. Evaluation of healed Colles' fractures. $J$ Bone Joint Surg [Am] 1951 ;33-A :895-907.

Golden GN. Treatment and prognosis of Colles' fracture. Lancet $1963 ; \mathrm{i}: 511-5$.

Lidström A. Fractures of the distal end of the radius: a clinical and statistical study of end results. Acta Orthop Scand 1959; Suppl 41.

Müller ME, Allgöwer M, Schneider R, Willenegger H. Manual of internal fixation: techniques recommended by the $A O$ Group. 2 nd ed. Berlin etc: Springer-Verlag, 1979.

Pool C. Colles' fracture: a prospective study of treatment. J Bone Joint Surg $[B r] 1973 ; 55-B: 540-4$.

Salter RB, Simmonds DF, Malcolm BW, Rumble EJ, Macmichael D, Clements ND. The biological effect of continous passive motion on the healing of full-thickness defects in articular cartilage: an experimental investigation in the rabbit. J Bone Joint Surg [Am] 1980;62-A :1232-51.

Sarmiento A, Pratt GW, Berry NC, Sinclair WF. Colles' fractures: functional bracing in supination. J Bone Joint Surg [Am] 1975; 57-A:311-7.

Smaill GB. Long-term follow-up of Colles' fracture. J Bone Joint Surg [Br] $1965 ; 47-\mathrm{B}: 80-5$.

Stewart HD, Innes AR, Burke FD. Functional cast-bracing for Colles' fractures: a comparison between cast-bracing and conventional plaster casts. J Bone Joint Surg [Br] 1984;66-B:749-53.

van der Linden W, Ericson R. Colles' fracture: how should its displacement be measured and how should it be immobilized? $J$ Bone Joint Surg [Am] 1981 ;63-A:1285-8. 